\title{
When do caregivers ignore the veil of ignorance? An empirical study on medical triage decision-making
}

\author{
Azgad Gold ${ }^{1} \cdot$ Binyamin Greenberg ${ }^{2} \cdot$ Rael Strous ${ }^{3} \cdot$ Oren Asman $^{4}(\mathbb{C}$
}

Accepted: 4 December 2020 / Published online: 4 January 2021

(c) The Author(s), under exclusive licence to Springer Nature B.V. part of Springer Nature 2021

\begin{abstract}
In principle, all patients deserve to receive optimal medical treatment equally. However, in situations in which there is scarcity of time or resources, medical treatment must be prioritized based on a triage. The conventional guidelines of medical triage mandate that treatment should be provided based solely on medical necessity regardless of any non-medical value-oriented considerations ("worst-first"). This study empirically examined the influence of value-oriented considerations on medical triage decision-making. Participants were asked to prioritize medical treatment relating to four case scenarios of an emergency situation resulting from a car collision. The cases differ by situational characteristics pertaining to the at-fault driver, which were related to culpability attribution.

In three case scenarios most participants gave priority to the most severely injured individual, unless the less severely injured individual was their brother. Nevertheless, in the aftermath of a vehicle-ramming terror attack most participants prioritized the less severely injured individual ("victim-first").

Our findings indicate that when caregivers are presented with concrete highly conflictual triage situations their choices may be based on value-oriented considerations related to contextual characteristics of the emergency situation. Philosophical and practical ramifications of our findings are discussed.
\end{abstract}

Keywords Decision making $\cdot$ Blame attribution $\cdot$ Medical ethics $\cdot$ Resource allocation $\cdot$ Terror $\cdot$ Triage

\section{Introduction}

Under optimal conditions, all patients have an equal right to medical care. Nevertheless, limited medical resources in emergency situations, mass disaster and epidemics, necessitate priority setting, or medical triage (Christian et al. 2006). Scanty public medical resources should be distributed prudently, effectively, in a just and fair manner (Hartman 2003; Sztajnkrycer et al. 2006; Moskop and Iserson

Oren Asman

asman@tauex.tau.ac.il

1 Forensic Psychiatry Unit, Yehuda Abarbanel Mental Health Center, Bat Yam, Israel

2 Adolescent Psychiatry Department, Beer Yaakov-Ness Ziona Mental Health Center, Beer Yaakov, Israel

3 Psychiatry Department, Mayanei Hayeshua Medical Center, Bnei Brak, Israel

4 Nursing Department, School of Health Professions, Sackler Faculty of Medicine, Tel Aviv University, Tel Aviv-Yafo, Israel
2007; Beauchamp and Childress 2012). Therefore, triage is inherently associated with ethical challenges (Domres et al. 2001; Burkle and Burkle 2015; American College of Emergency Physicians 2017). The COVID-19 epidemic has brought forth ethical challenges related to triage (Emanuel et al. 2020; Truog et al. 2020), including their psychological burden (Greenberg et al. 2020; Rosenbaum 2020).

From a medical perspective, common triage determinants include type of injury, illness severity and subsequent prospects of recovery. Utilitarian reasoning indicates that treatment will be restricted to patients who have a reasonable chance to survive. Thus, after separating out the moribund patients, the conventional "worst-first" approach holds that treatment should be provided impartially according to the urgency of the need for care, namely, those with the most serious condition will be treated first. Nevertheless, different triage policies may be applied to different domains. For example, Disaster triage refers to situations in which medical resources become extremely rare. Under this condition, caregivers are required to allocate the very limited resources at their disposal maximizing the utility gained by the use of 
those resources, regardless of other principles such as equality or the rights of the patients (Wagner and Dahnke 2015). In military settings, utilitarian considerations may overcome egalitarianism, thus dictating that combat soldiers will be treated before civilians, and certainly before enemy soldiers, regardless of the severity of their injury (Swan and Swan 1996; Sidel and Levy 2003; Task Force on Quality Control of Disaster Management 2003; Allhoff 2008). Battlefield medicine originally was an extreme version of utilitarianism as it did not aim to save the most lives but to gain the most utility in the combat situation (Baker and Strosberg 1992). The justification for sending wounded soldiers back to the frontlines as soon as possible stemmed from the desire to achieve victory at the cost of losing lives. During the COVID-19 pandemic, Italy issued new utilitarian-oriented triage guidelines that prioritize the allocation of resources to patients that are more likely to be discharged after a short period of time (Vergano et al. 2020). The utilitarian patterns of emergency triage may lead to ignoring moral principles such as patient rights and equality and thus create long-term emotional distress among triage nurses (Wagner and Dahnke 2015).

Utilitarian reasoning may be quantitative or qualitative oriented, namely focusing on saving the most lives possible or as saving the lives that are considered most useful to society (Baker and Strosberg 1992). However, from deontological and egalitarian perspectives, all individual have equal rights that should not be violated even for the collective benefit of the society (Rawls 1971, p. 28).

Justice-oriented perspectives on resource allocations may focus on actions or properties of those in need of scarce resources. Basically, the just desert approach holds that wrongdoing must be balanced by a punishment proportionate to the moral wrong committed (Kant 1952/1790, p. 446). Thus, medical personnel who are exposed to information indicating that a patient is involved in illicit activity may seek to punish the offender based on justice concerns (Carlsmith, Darley and Robinson 2002). At the same time, a desert-based justice approach that aims at rewarding agents based on prior activity (Feinberg 1970) may lead to prioritizing the medical treatment of a virtuous person.

While the clinical, ethical and policy related dimensions of medical triage have been extensively discussed in the literature (Society of Academic Emergency Medicine Ethics Committee 1995; Robertson-Steel 2006; Iserson and Moskop 2007; Moskop and Iserson 2007; Bodansky 2009; Mackway-Jones et al. 2013), empirical research is scarce pertaining to "real life", intuitive perception, opinions and attitudes of health care providers concerning triage. Previous work on moral judgments in life-and-death decision-making contexts, showed people are affected by emotions, cognitions and worldviews, when faced with a moral dilemma. For instance, prioritizing older children over young children, that appears to be driven by their having had more invested in their lives, their better developed social relations, and their greater understanding of death (Goodwin and Landy 2014), or when prioritizing family over strangers which shows the importance of special obligations in the structure of moral judgment (McManus et al. 2020). Several studies have aimed at identifying factors that affect triage decision-making (Garrouste-Orgeas et al. 2003; Chung 2005; Göransson et al. 2008; Klein et al. 2016; Gopalan and Pershad 2019), mostly focusing on patient, caregivers and environmental measures (such as patient condition severity, caregiver level of experience and bed availability), or on assessing triage protocol implementation (Considine et al. 2007; Sapp et al. 2010; Hegazy et al. 2012).

Very few studies have examined caregivers' attitudes to ethical issues arising from complex triage situations (Vincent 1990). In this context, Vincent indicated the difference between what a physician actually does and what he or she believes should be done with regard to various ethical questions (Vincent 1999).

The lack of empirical studies of this sort is quite surprising. In highly emotionally charged emergency situations, when medical teams in the field are in turmoil, triage decisions may be guided, at least in part, by moral intuition, especially if guidelines are not clear or they are perceived as inappropriate. Moreover, empirical data that highlights the important role of affect-based intuitions in the generation of moral judgment and reasoning (Haidt 2001; SinnottArmstrong et al. 2010) further raise the need for empirical study on real-life triage decision-making by caregivers. It is essential to determine whether there is a disparity between accepted triage rules and caregivers' moral intuitions regarding treatment allocation. An ideal test case for such potential disparity may be related to emotionally provoking contentious triage situations.

\section{Human-caused medical emergencies}

As a general rule, triage is expected to be applied exclusively based on medical necessity ("worst-first"), leaving aside any value judgments pertaining to patients' personal characteristics or to the context of the situation. According to this approach, all medical emergencies are equal. Thus, any details concerning the identity of those injured or the cause of the situation (e.g. a terrorist attack, car accident, or a natural disaster) should be irrelevant. Caregivers are expected to provide treatment as if there were operating behind a veil of ignorance that keeps them blind to contextual circumstances and their own worldviews, which may unjustifiably bias their judgement (Rawls 1971).

Should triage remain blind under all circumstances with no exception? 
This question has previously been hotly debated regarding the aftermath of terrorist attacks where both terrorists and their victims require emergency medical care (Kipnis 2003; Gold and Strous 2017a; Lederman and Voo 2019). The dilemma is whether badly injured victims should be prioritized in receiving medical treatment, even if the terrorist who caused their injuries suffers from a more severe condition (i.e., worst-first or victim-first).

Why should the terrorist-triage dilemma seem to be more contentious than other triage situations? Blame attribution theory may provide an answer, at least partially (Heider 1958; Kelley 1967; Kelley and Michela 1980; Alicke 2000; Nadelhoffer 2006; Gold 2011).

Human cognitive and emotional reactions to events and behaviors are based on causality-related interpretations (Sperber et al. 1996). Blame or culpability attribution is influenced by relatively unconscious, spontaneous evaluations which are affective reactions to the harmful event and the people involved (Alicke 2000). Culpability evaluations relating to agents and actions, among other components, include perceptions concerning causation, intentions, foresight and self-control. In harmful situations in which agents' behavior is perceived as internally-controlled and driven by premeditated negative or destructive intention and motivation, blame attribution seems to intensify (Knobe et al. 2012). Conversely, constraints on the at-fault agent, where he or she is perceived as externally-controlled, potentially mitigate blame. Thus, a person who acts accidentally or unconsciously, is perceived as less blameworthy.

Given the above, it seems reasonable to assume, that specific human-caused medical emergency events, as opposed to a natural disaster, may provoke varying emotional reactions. Thus, in situations in which an agent is held responsible for the injury of himself and others, by-standers may be inclined to "owngrade" his or her priority for medical treatment due to unconscious retributive or punitive intuitions. Given the high level of hostility and rage that is generated by terror (Huet et al. 2019), it is not surprising that the terrortriage dilemma elicits such heated controversy.

\section{Triage decision-making by caregivers}

This study is a survey of caregivers' opinions and views about triage in ethically challenging situations. At the same time, the study intends to illuminate the decision-making process that underlies caregivers' attitudes and opinions about triage, and more specifically, the influence of valueoriented considerations related to culpability on medical triage.

Based on the aforementioned reasoning, we developed a questionnaire presenting four medical emergency case scenarios that necessitate the urgent allocation of medical treatment.
In all four case scenarios, the emergency situation resulted from a car collision. Both the driver who caused the collision and an individual in another car were in need of emergency medical treatment. The driver responsible for the collision was in the worst medical condition. The outcome of the accident, in terms of casualties, was similar with regard to all four cases (two dead children in addition to the injured individual in the other car).

In order to study the role of value-oriented considerations on medical triage decision-making process, a "culpability gradient" was built. Namely, the characteristics pertaining to the at-fault driver differ for each of the four cases in a manner that had been hypothesized to modify the culpability attribution, as follows:

In the first case scenario, the offending driver was presented as a terrorist who committed a "car-ramming" attack. The second case referred to $a$ drunk driver, and the third case to a driver who suffered from $a$ sudden loss of consciousness. The selection of these three character-types was based on the assumption that the terrorist, who acts willingly and intentionally with clear motivation to harm others, will be morally perceived more negatively than the drunk driver, whose behavior would be regarded as being negligent but not malicious. Likewise, we assumed that the driver who lost consciousness (fully externally-controlled) will be perceived as the least blameworthy in comparison to the terrorist and the drunk driver.

In addition to these three character-types, we were curious to investigate whether a positive, altruistic intention of an agent may play a mitigating role in terms of culpability for the collision, and if so, what would be its influence on the decision-making process regarding the medical triage. Therefore, the fourth case scenario referred to a first-responder volunteer driver who caused a collision while he was on his way to provide medical assistance.

After the presentation of each case-scenario separately, the subjects were asked to answer several questions related to the medical triage of the driver and the other individual (as will be detailed in the next section). Since the driver responsible for the collision was in the worst medical condition in all four case scenarios, according to the conventional "worst-first" approach, in all four cases, the at-fault driver should have been selected to be treated first. Thus, any different priority setting would negate the "worst-first" approach and may reflect contextual adjustments to triage based on value-oriented considerations. 


\section{Method}

\section{Tools}

A self-administered questionnaire was specifically designed for this research by the authors. It was reviewed by experienced colleagues. The final version reflected their comments. The questionnaire consisted of three sections: (a) Demographics (gender, age, religion, religiosity, political orientation); (b) Four separate sections of case scenarios followed by triage-related questions (c) A question relating to the perceived triage priorities with regard to each case according to medical ethics rules.

In section (b), following each case scenario (as mentioned above), the subjects were asked to make a choice who should be treated first - the at-fault driver who was injured very severely but his life can be saved by immediate medical treatment or the individual in the other car who was severely injured and unless he receives treatment there is a potential danger to his life, albeit at a lower level of urgency in comparison to the life-threating condition of the at-fault driver.

For each scenario the participants were asked the following: (1) According to your conscience and worldview, who should be treated first?; (2) If you were the physician at the scene who would you treat first?; (3) Who do you think most physicians in your country would have treated first?; (4) If you were the physician at the scene, and found out that the other injured individual (i.e., the less severely injured) is your brother, who would you treat first?

The participants provided their answers on a categorical scale. This scale reflected both their choice relating to the identity of the individual who should be treated first, and the level of certainty they felt with regard to their choice, as follows: "absolutely sure", "sure", "probably", or "possibly" that priority should be given to the at-fault driver (e.g. terrorist/drunk/unconscious/first-aid volunteer driver, according to the "worst-first" approach), or "absolutely sure", "sure", "probably", "possibly" that priority should be given to the individual in the other car (i.e., "victim-first").

In order to neutralize any order-of-presentation bias, the four case scenarios were presented in a randomized reversed manner (i.e., either terrorist, drunk, unconscious, first-aid volunteer or first-aid volunteer, unconscious, drunk, terrorist).

The final question for each case scenario section was: in your opinion, should the medical triage in this case be determined by the conscience and worldview of the caregiver at the scene? Subjects graded their answer on a four-option categorical scale, ranging from: "there is no place for determining the triage based on the caregiver's conscience and worldview", to "the triage should be made solely based on the caregiver's conscience and worldview".
Table 1 Demographic data

\begin{tabular}{ll}
\hline Characteristics $(\mathrm{N}=122)$ & Frequency \\
\hline Sex & $9.7 \%$-Male \\
Religion & $90.3 \%$-Female \\
& $83 \%$-Jewish \\
& $10 \%$-Muslim \\
& $3.3 \%$-Christian \\
& $1.7 \%$-Other \\
Religiosity & $53.3 \%$-Secular \\
& $26.7 \%$-Traditional \\
& $19.2 \%$-Religious \\
Political orientation & $0.8 \%$-Other \\
& $41.8 \%$-Right \\
& $28.7 \%$-Left \\
& $15.5 \%$-Center \\
& $14 \%$-Other \\
\hline
\end{tabular}

After answering all the questions relating to each case scenario (section), subjects could not reverse or change their responses.

Section (c) included a question that referred separately to the four case scenarios: "According to the rules of medical ethics, who should be treated first?". In order to neutralize any response bias to this question, it was presented last, after all case scenarios had been presented and answered. Participants rated medical priority for each case scenario on the same categorical scale that was presented above with regard to section (b).

\section{Participants}

Data was collected voluntarily from one hundred and eightytwo nursing students at the Nursing Department of a university in Israel. The inclusion criteria were students who attended class, consented to study participation, signed the informed consent form and completed the questionnaire. Exclusion criteria were students who did not wish to participate or did not sign the consent form. In addition, data from participants who did not respond to more than one question were removed. One hundred and twenty-two respondents who approved the informed consent form and completed the questionnaire were included in the final sample. Among them, eighty-three were registered nurses in advanced training or MA studies, thirty-nine were third-year BA nursing students. Most of the subjects were females (90.3\%) and 
Fig. 1 Percentage of treatment priority given to the most severely injured for the four case scenarios

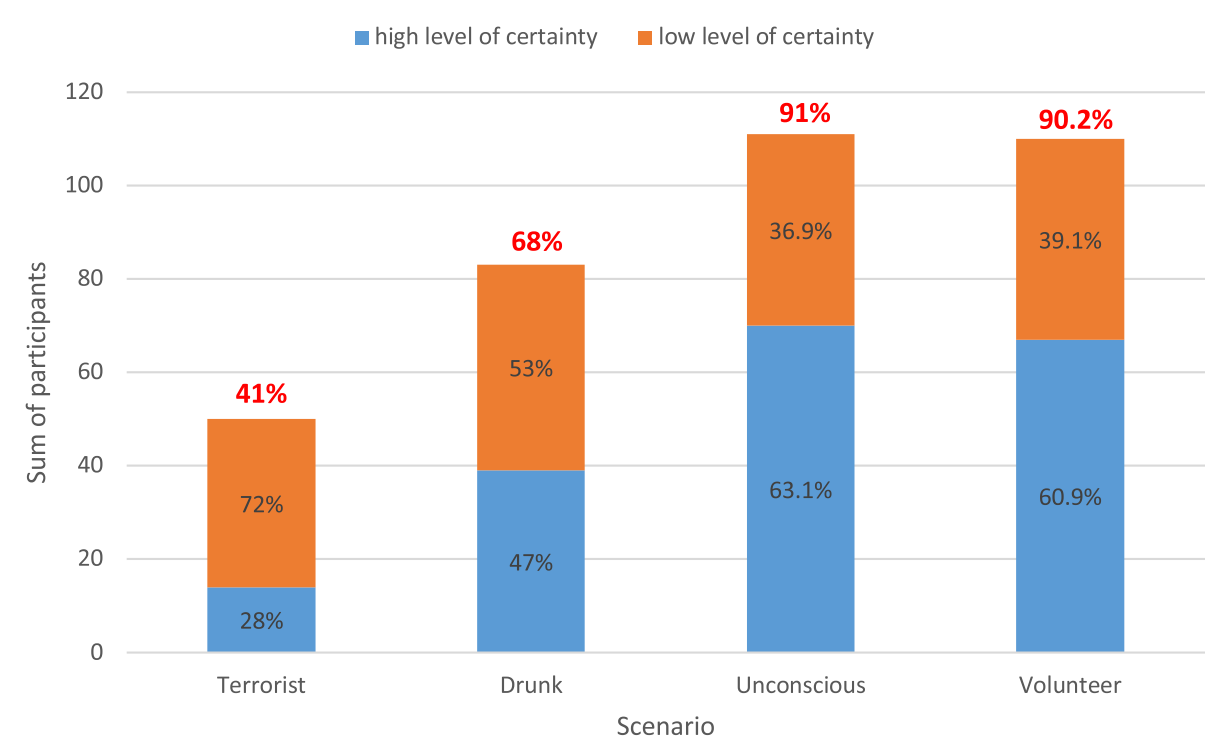

Jewish $(83 \%)$. The mean age was $31.3(\mathrm{SD}=8.13)$ [demographics are presented in Table 1]. ${ }^{1}$

The link to the survey was given to the participants in each class during the final $15 \mathrm{~min}$ of the lesson. Most participants completed it within 12-15 min. This was done on four occasions between April 2019 and November 2019.

\section{Procedure}

Data was collected using the Qualtrics online platform software, Copyright (C) 2019 Qualtrics, Provo, UT, USA. https ://www.qualtrics.com.

\section{Ethical considerations}

The university's ethics committee approved the questionnaire. Informed consent forms were signed anonymously by the participants.

\section{Data analysis}

Data was analyzed using SPSS v. 25 (IBM, USA) and tables and graphs were prepared using Excel 2016 MSO (Microsoft Corporation, USA). Descriptive statistics were performed to examine in-group differences. Frequency analysis were performed to examine between-group differences with regards to demographic characters and research variables.

\footnotetext{
${ }^{1}$ No association was found between participants' religiosity and the medical treatment priority made by them using a Chi-Square test (all $p$ 's $>.10$ ).
}

\section{Results}

\section{Between subjects analysis}

No significant differences relating to medical priority decisions were found between subjects with regard to a particular group (e.g. BA vs. MA students), including their religious background. Thus, further analysis was performed on all subjects as one group.

\section{Different priority setting between scenarios}

Most participants gave medical priority to the most severely injured, the at-fault driver, ("worst-first") except for the terrorist case scenario, when they responded to the most practical question: "If you were the physician at the scene who would you treat first?", as shown in Fig. 1.

The percentage of participants who prioritized the most severely injured at-fault driver ("worst-first") with regard to the abovementioned question followed the subsequent order: terrorist $(41 \%)$, drunk driver $(68 \%)$, unconscious driver $(91 \%)$ and the first aid volunteer driver (90.2\%). A similar increasing pattern was found with regard to presence of a high level of certainty (i.e., "absolutely sure" or "sure") relating to the decision to prioritize the most severely injured at-fault driver, as follows: $28 \%$ high level of certainty in the case of the terrorist at-fault driver, $47 \%$ high level of certainty for the drunk, $63.1 \%$ for the first aid volunteer and the $60.9 \%$ for the driver who suddenly lost consciousness. Nevertheless, when participants responded to the questions: "Who do you think most physicians in your country would have treated first?" and "Who should be prioritized based on medical ethics rules"? the majority of the participants gave medical priority to the most severely injured at-fault driver, including for the terrorist case scenario. With regard to all 
Table 2 Medical treatment priority for all four case scenarios

\begin{tabular}{|c|c|c|c|c|c|c|c|c|}
\hline \multirow{2}{*}{$\begin{array}{l}\text { Scenario ques- } \\
\text { tion }\end{array}$} & \multicolumn{2}{|l|}{ Terrorist } & \multicolumn{2}{|l|}{ Drunk } & \multicolumn{2}{|l|}{ Unconscious } & \multicolumn{2}{|l|}{ Volunteer } \\
\hline & At-fault driver & $\begin{array}{l}\text { The other } \\
\text { individual }\end{array}$ & At fault driver & $\begin{array}{l}\text { The other } \\
\text { individual }\end{array}$ & At fault driver & $\begin{array}{l}\text { The other } \\
\text { individual }\end{array}$ & At-fault driver & $\begin{array}{l}\text { The other } \\
\text { individual }\end{array}$ \\
\hline $\begin{array}{l}\text { Priority based } \\
\text { on your } \\
\text { conscience }\end{array}$ & $\begin{array}{l}(\mathrm{N}=37) \\
30.3 \%\end{array}$ & $\begin{array}{l}(\mathrm{N}=85) \\
69.7 \%\end{array}$ & $\begin{array}{l}(\mathrm{N}=66) \\
54.1 \%\end{array}$ & $\begin{array}{l}(\mathrm{N}=56) \\
45.9 \%\end{array}$ & $\begin{array}{l}(\mathrm{N}=114) \\
93.4 \%\end{array}$ & $\begin{array}{l}(\mathrm{N}=8) \\
6.6 \%\end{array}$ & $\begin{array}{l}(\mathrm{N}=109) \\
89.3 \%\end{array}$ & $\begin{array}{l}(\mathrm{N}=13) \\
10.7 \%\end{array}$ \\
\hline $\begin{array}{l}\text { Priority if you } \\
\text { were the } \\
\text { physician at } \\
\text { the scene }\end{array}$ & $\begin{array}{l}(\mathrm{N}=50) \\
41 \%\end{array}$ & $\begin{array}{l}(\mathrm{N}=72) \\
59 \%\end{array}$ & $\begin{array}{l}(\mathrm{N}=83) \\
68 \%\end{array}$ & $\begin{array}{l}(\mathrm{N}=39) \\
32 \%\end{array}$ & $\begin{array}{l}(\mathrm{N}=111) \\
91 \%\end{array}$ & $\begin{array}{l}(\mathrm{N}=11) \\
9 \%\end{array}$ & $\begin{array}{l}(\mathrm{N}=110) \\
90.2 \%\end{array}$ & $\begin{array}{l}(\mathrm{N}=12) \\
9.8 \%\end{array}$ \\
\hline $\begin{array}{l}\text { Priority by } \\
\text { most physi- } \\
\text { cians }\end{array}$ & $\begin{array}{l}(\mathrm{N}=67) \\
54.9 \%\end{array}$ & $\begin{array}{l}(\mathrm{N}=55) \\
45.1 \%\end{array}$ & $\begin{array}{l}(\mathrm{N}=94) \\
77 \%\end{array}$ & $\begin{array}{l}(\mathrm{N}=28) \\
23 \%\end{array}$ & $\begin{array}{l}(\mathrm{N}=112) \\
91.8 \%\end{array}$ & $\begin{array}{l}(\mathrm{N}=10) \\
8.2 \%\end{array}$ & $\begin{array}{l}(\mathrm{N}=108) \\
89.3 \%\end{array}$ & $\begin{array}{l}(\mathrm{N}=13) \\
10.7 \%\end{array}$ \\
\hline $\begin{array}{l}\text { Priority if } \\
\text { the other } \\
\text { individual is } \\
\text { your brother }\end{array}$ & $\begin{array}{l}(\mathrm{N}=13) \\
10.7 \%\end{array}$ & $\begin{array}{l}(\mathrm{N}=109) \\
89.3 \%\end{array}$ & $\begin{array}{l}(\mathrm{N}=19) \\
15.6 \%\end{array}$ & $\begin{array}{l}(\mathrm{N}=103) \\
84.4 \%\end{array}$ & $\begin{array}{l}(\mathrm{N}=43) \\
35.2 \%\end{array}$ & $\begin{array}{l}(\mathrm{N}=79) \\
64.8 \%\end{array}$ & $\begin{array}{l}(\mathrm{N}=31) \\
25.4 \%\end{array}$ & $\begin{array}{l}(\mathrm{N}=91) \\
74.6 \%\end{array}$ \\
\hline $\begin{array}{c}\text { Priority based } \\
\text { on medical } \\
\text { ethics rules }\end{array}$ & $\begin{array}{l}(\mathrm{N}=87) \\
71.3 \%\end{array}$ & $\begin{array}{l}(\mathrm{N}=35) \\
28.7 \%\end{array}$ & $\begin{array}{l}(\mathrm{N}=95) \\
77.9 \%\end{array}$ & $\begin{array}{l}(\mathrm{N}=27) \\
22.1 \%\end{array}$ & $\begin{array}{l}(\mathrm{N}=111) \\
91 \%\end{array}$ & $\begin{array}{l}(\mathrm{N}=11) \\
9 \%\end{array}$ & $\begin{array}{l}(\mathrm{N}=109) \\
89.3 \%\end{array}$ & $\begin{array}{l}(\mathrm{N}=13) \\
10.7 \%\end{array}$ \\
\hline
\end{tabular}

Fig. 2 Priority given to terrorist at-fault driver based on varying determinants and decision level of certainty

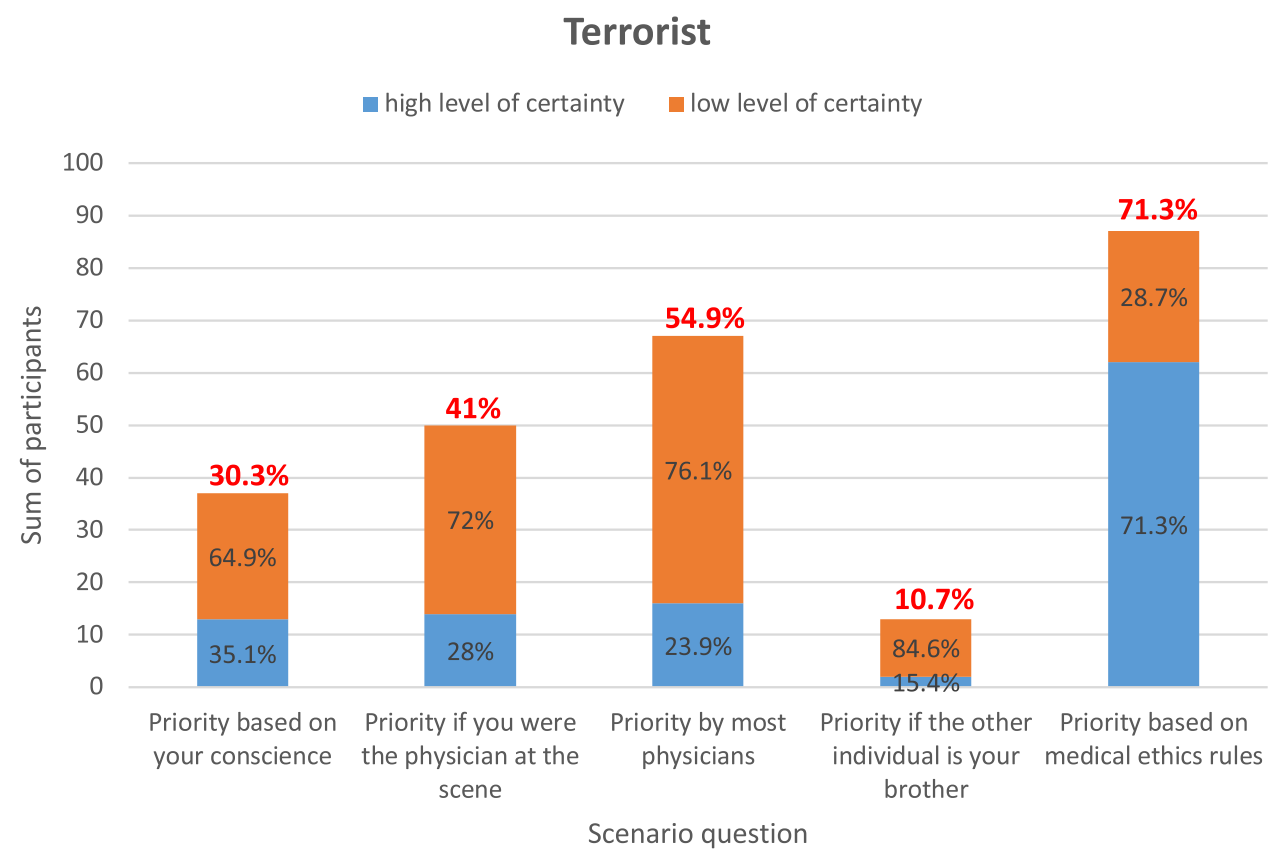

four case scenarios, medical priority was given to the least severely injured other individual ("victim-first") when participants were asked what their first medical priority would be if that other individual was found to be their brother.

\section{Different priority setting within scenarios}

Data pertaining to participants' medical priority for all scenarios is shown in Table 2 .

\section{Terrorist scenario}

Participants demonstrated variability with regard to the medical treatment priority that should be given to the most severely injured terrorist at-fault driver, when they responded to questions relating to different determinants, as shown in Fig. 2.

When participants were asked to prioritize medical treatment based on their conscience and worldview, only $30.3 \%$ gave first priority to the terrorist at-fault driver. However, 
Fig. 3 Priority given to unconscious at-fault driver based on varying determinants and decision level of certainty

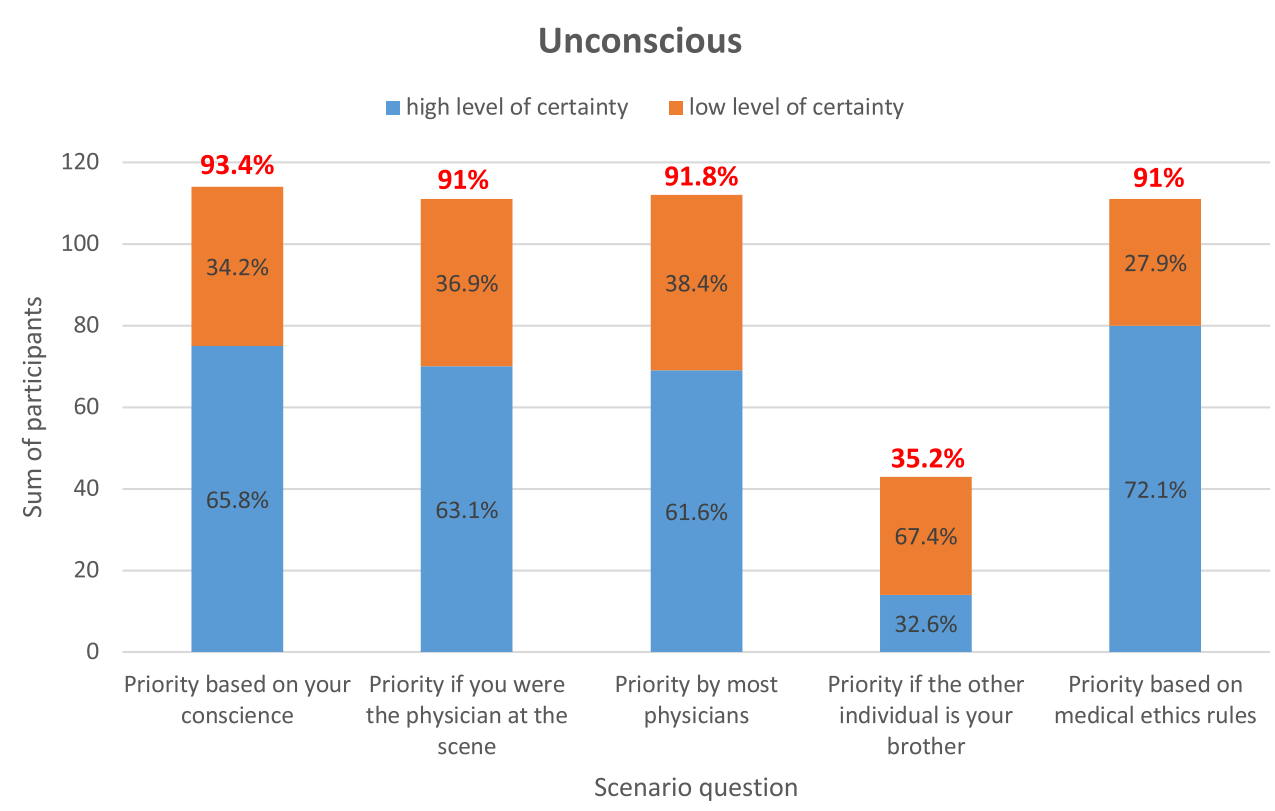

when they were asked what they would have done if they were the physician at the scene, $41 \%$ gave first priority to the terrorist causing the collision. The majority of the participants gave first priority to the terrorist at-fault driver when they were asked to estimate who most physicians in their country would have prioritized (55.2\%) and who should be prioritized based on medical ethics rules (71.3\%). First priority to be given to the terrorist at-fault driver was lowest $(10.7 \%)$ when respondents referred to a hypothetical situation in which the less severely injured individual was their brother. Most participants who prioritized the terrorist atfault driver for each of the abovementioned determinants, rated their decision with low level of certainty, except for the question referring to the priority that should be given based on medical ethics rules.

In order to highlight the pattern of participants' responses relating to the terrorist causing the collision, it would be useful to compare these responses to the data relating to a different case scenario.

\section{Unconscious driver scenario}

Compared to the terrorist scenario, a different pattern of responses was found with regard to the driver who lost consciousness, as shown in Fig. 3.

In this case, there were no notable differences between participants' priority setting based on different determinants. The vast majority of participants prioritized the most severely injured unconscious at-fault driver based on their conscience and worldview (93.4\%) and on medical ethics rules $(91 \%)$, if they were the doctor at the scene $(91 \%)$, and they estimated that most physicians at their country would have made the same decision (91.8\%). Nevertheless, similar to all four case scenarios, medical priority was given to the least severely injured other individual when participants were asked what their first medical priority would have been if that other individual was found to be their brother. Notably, the highest percentage (35.2\%) of giving first medical priority to the at-fault driver when the other less severely injured individual was presented as "your brother", was given to the driver who lost consciousness (as shown in Table 2).

In contrast to findings with regard to the terrorist scenario, most participants who prioritized the unconscious atfault driver, rated their decision with high level of certainty, except for the scenario in which the other less severely injured individual was presented as their brother.

Of note, the pattern of responses relating to the unconscious and first-responder volunteer case scenarios was quite similar (as shown in Table 2).

\section{Between-group differences-Demographic characters and research variables}

\section{Terrorist scenario}

The number of participants who rated their decision with high level of certainty relating to the terrorist at-fault driver scenario (either prioritizing the terrorist causing the collision or the other individual) was measured and compared with their self-reported political leanings.

Out of 42 participants who demonstrated high level of certainty relating to their decision to prioritize the least severely injured other individual ("victim-first") if they were the doctor at the scene, 22 identified as politically right wing, and 3 as left wing (the rest of the respondents defined 
themselves as either "center" (13) or "other"(4). Conversely, out of 13 participants who demonstrate high level of certainty that they would have medically prioritized the terrorist driver if they were the doctor at the scene ("worst-first"), 2 identified as politically right wing, and 6 as left wing ("center" 1, "other" 4). Although these numbers are low in terms of statistical analysis, it seems relevant to descriptively highlight these findings.

Of note, $71.4 \%$ of those who prioritized the other less severely injured individual (victim-first) with a high level of certainty expressed the view that caregivers' conscience and worldview should have a significant role in this triage decision. However, none of the participants who demonstrated a high level of certainty regarding the choice to prioritize the terrorist causing the collision held the view that caregivers' conscience and worldview should play a significant role in the triage decision.

\section{Discussion}

This study focused on caregivers' attitudes relating to medical triage, with special emphasis on the implementation of the conventional "worst-first" principle in various humancaused medical emergencies. We tested the hypothesis that triage preferences will be influenced by different degrees of culpability attribution towards the most severely injured individual (in our case, the at-fault driver). This study contributes to the limited data specifically targeting the decision-making process of caregivers' attitudes to triage. To the best of our knowledge, it is the first study that empirically examines the attitudes of caregivers to highly challenging triage situations, and the first to suggest the relevance of blame attribution perceptions to medical treatment priority setting.

The participants in our study were asked to provide a choice between two options, two severely injured individuals, as if they were the physician at the scene. In general, the moral dilemma in triage, as opposed to other morally challenging conflicts, does not involve the choice between good and bad action, but rather, a choice between two options that both are good in essence - providing treatment to an injured individual.

Indeed, in most real-life medical triage situations, firstaid responders are operating behind an epistemic veil of ignorance relating to the contextual circumstances of the emergency situation, simply because they arrive at the scene without knowing all the circumstances that have led to the emergency event. However, as it may actually happen in some situations (Gold and Strous 2017b), our participants were asked to set medical priority after the epistemic veil of ignorance has been removed and the specific circumstances that had led to the emergency situation were revealed.
Our main findings show that overall the "worst-first" approach was applied with regard to most scenarios. However, in highly conflictual situations, the context of the emergency situation and personal characteristics relating to the injured individuals in the scene affected the priority setting of medical treatment and led to a deviation from the "worstfirst" principle.

Most participants (59\%) gave priority to the less severely injured individual ("victim-first") had they been the physician at the scene in the aftermath of a vehicle-ramming terror attack, in spite of the fact that the terrorist had been injured more severely. At the same time, most participants (71.3\%) acknowledged that the priority based on medical ethics rules mandates that the most severely injured terrorist would be treated first. In addition, the majority of the respondents $(54.9 \%)$ estimated that most physicians in their country would have prioritized the most severely injured terrorist. Thus, it seems that participants" "real life" prioritysetting relating to this case scenario ("had they been the physician at the scene") was influenced by conflicting personal moral intuitions and perceptions $(69.7 \%$ prioritized the other less severely injured individual based on their conscience and worldview).

In addition, with regard to all four case scenarios, the majority of the participants, however not all, reported that in a "real life" situation ("had they been the physician at the scene") they would have treated first their brother even though he would not have been the most severely injured individual in the scene.

Our findings also suggest that culpability attribution perceptions relating to the most severely injured individual may affect caregivers' triage decision-making process. When participants responded to the question: "If you were the physician at the scene who would you treat first?", their likelihood to prioritize the most severely injured at-fault driver and their level of certainty relating to this decision were inversely connected to the "culpability gradient" (terror $<$ drunk $<$ unconscious). Namely, the percentage of participants who prioritized the most severely injured atfault driver demonstrate the following pattern: terrorist $41 \%$; drunk $68 \%$; unconscious $91 \%$ (with $28 \%, 47 \%$, and $63.1 \%$ high level of certainty, accordingly).

Our results highlight a disparity that exits between conventional triage principles ("worst-first") and "real life" caregivers' attitudes in highly conflictual situations, as follows.

According to the "worst-first" approach:

(P1) A triage related to patients who all have a chance to survive should be determined solely based on medical necessity.

(P2) In the terror-triage case-scenario the injured atfault terrorist has a chance to survive and he is the most severely injured patient. 
Therefore, (C) the at-fault terrorist should receive treatment first.

However, the majority of the participants in our study seemed to hold the following decision-making process:

(P1) Triage related to patients who all have a chance to survive should be determined solely based on medical necessity, except in rare circumstances.

(P2) The terror-triage situation, in which the most severely injured individual is the at-fault terrorist and there is also a severely injured victim, is a rare circumstance.

Therefore, $(\mathrm{C})$ the victim should receive treatment first.

In addition, contrary to the "worst-first" approach, the majority of our participants seemed to adhere to the following decision-making process:

(P1) Triage related to patients who all have a chance to survive should be determined solely based on medical necessity, except in rare circumstances.

(P2) A triage situation, in which my brother is severely injured albeit he is not the most severely injured individual, is a rare circumstance.

Therefore, (C) my brother should receive treatment first.

The participants responded to moral dilemmas. However, it remains open to a debate whether the above-mentioned decision-making process is actually a moral judgment, and if so, what kind of moral judgement it is (intuitive or reflective). For example, it may be argued, that participants who demonstrated a predilection to prioritize their less severely injured brother were not perceiving their response as morally appropriate. They may actually think that their choice is amoral, but they were choosing it anyway because saving their brother seemed more important. Interestingly, participants' clear preference for their first-degree relative seems be interpreted differently by different meta-ethical schools. While the consequentialist and deontological views may categorize the brother prioritization as a moral failure due to lack of impartiality, ethics-of-care theorists may be more receptive to an agent who shows a strong commitment to someone who has a meaningful relationship with the decision-maker (Gilligan 1982; Held 2005).

Nevertheless, with regard to the terrorist case scenario, it seems that most participants who prioritized the less severely injured victim with a high level of certainty did so based on a moral judgment that has led them to the intuitive or reflective conclusion that this is morally appropriate. This assumption seems to derive from the fact that $71.4 \%$ of this group expressed the view that caregivers' conscience and worldview should have a significant role in this triage decision. In other words, their selection was in accordance with their conscience and worldview.

Our findings are open to different interpretations, which arguably related to different ethical and meta-ethical theoretical premises. More specifically, our finding relating to the "victim-first" view that was adopted by the majority of the respondents with regard to the terrorist scenario, may parallel Greene's theory pertaining to the "tribal" characteristics of moral intuitions (Greene 2003, 2013, 2017). In addition, our findings may receive different interpretation by opposing views within the spectrum relating to the relation between descriptive moral psychology ("is") and prescriptive moral philosophy ("ought"), or the epistemic and normative status of moral intuitions (Alexander and Weinberg 2014; Boyd and Nagel 2014; Luetge et al. 2014; Stich and Tobia 2016; Williamson 2016). According to the view that finds philosophical significance in laypersons' moral intuitions, the disparity that exits between conventional triage principles ("worst-first") and "real life" caregivers' attitudes in highly conflictual situations raises a serious question regarding the normative validity of the ultimate "worstfirst" principle. If our findings are replicated, it may suggest that the unconditional worst-first triage principle, that mandates a fully blinded triage behind a veil of ignorance, in every emergency situation with no exception is a myth, at least with regard to highly conflictual circumstances. Thus, instead of arguing against caregivers who are required to operate under highly challenging situations that they should not ignore the perceived veil-of-ignorance-ideal, it may be prudent to reevaluate and consider the possibility that the execution of the worst-first approach in extreme circumstances ignores a valid moral voice that is deeply embedded in human intuition.

Regardless of the different interpretations that may explain our findings at the philosophical and psychological level, it is important to emphasize that our "layperson" participants are not random subjects, as it may usually be the case in most studies that relate to experimental philosophy (Knobe and Nichols 2014). Our subjects were nursing personnel in different stage of professional development. All of them will be, or already are, operating in real triage situations. Thus, from a practical perspective, the disparity between caregivers' perception relating to what they are expected to do in highly conflictual triage situations, and what they are inclined to do based on their conscience, may lead to moral distress (Oh and Gastmans 2015) and nonadherence to triage protocols. Therefore, educational and supportive interventions may be needed in order to minimize the moral distress associated with conflictual triage situations. In addition, on-site supervision may be required in order to minimize potential deviations from triage guidelines in such situations. Additional interesting questions pertaining to moral distress include the following: do participants 
who confront difficult triage situation during a study experience moral distress? If so, how they deal with it and what are the best means to address and mitigate their moral distress? This topic may be the subject of future evaluations.

This study has a few shortcomings; of which some are related to inherent limitations of survey research. First, selfreported data can often be biased (Podsakoff et al. 2003). Second, a selection bias may stem from the fact that only participants who were interested in sharing their thoughts, consented and completed the questionnaire, were included in the study. Third, our questionnaire included categorical parameters. As a result, study analysis was limited to descriptive analysis. This however does not in any way narrow assumptions that may be made from study data. Future study-design is planned to include continuous variables which will enable the use of more advanced statistical analysis. Furthermore, as a preliminary study, our "culpability gradient" has not been vigorously validated empirically. Another limitation relates to the generalizability of the findings. Our sample consisted of nursing students in Israel, most of them Jewish and female. Future research should aim to study triage decision-making in other countries and cultures and in other professions (medical and non-medical). Furthermore, triage involves a variety of roles, and the responsibility for it is not shared equally. The respondents of our study were nurses and future nurses. However, triage decisions in the hospital arena are usually made by physicians and in the field by paramedics. Thus, in order to better understand the potential role of moral intuitions in actual triage decisions, future study should focus on respondents who are physicians and paramedics.

In addition, the current study examined a relevant participants populations' normative perception regarding an extreme resource allocation dilemma. Since we were interested in the participants' naïve normative response, they were not instructed regarding the principles of equality, equity or fairness or the actions prescribed by each principle. Future studies may tackle participants' responses under priming of a specific justice perception or specific ethical guidelines like the ones made by national ethics comities during the COVID pandemic (Vergano et al. 2020).

Finally, inherent limitations exist in attempting to predict the actual behavior of caregivers in "real life" practice based on respondents' attitudes via a theoretical survey. This is especially true with regard to theoretical scenarios that may differ from real live situations in various aspects. For example, in real life emergency situations there is often more than one assisting person and additional help by different teams may be available. In addition, the antecedent cause of the medical emergency situation is mostly unknown to the medical personnel.

In spite of these limitations, our study may lead to further empirical research and philosophical analysis that focus on the role of moral intuitions in the medical arena. Moreover, our findings call for further empirical research relating to the practical aspects of triage, including the implementation of conventional triage policy in "real life" situations. This initiative seems to be especially needed today given the highly emotionally challenging Covid-19 crisis. If indeed "real life" triage decisions may be affected by caregivers' personal intuition, as our data suggest, medical resources may be allocated in a manner that deviates from standard triage protocols, either intentionally, subconsciously, or even surreptitiously. In fact, care ethics-oriented scholars argue that the conventional justice-oriented triage rules may not provide the most appropriate moral solution to various Covid-19 triage situations (Wirth et al 2020). Accordingly, medical supplies or ventilators may be diverted to caregivers' first-degree relatives, colleagues or close acquaintances who are in a relatively better condition in comparison to non-relatives, or caregivers may "downgrade" the priority of patients who are perceived blameworthy (e.g. a patient who either intentionally and deliberately violated or even ignored coronavirus confinement rules and subsequently infected others). Indeed, the Corona virus in a natural source of illness. However, the infection is transmitted by humans. Therefore, caregivers' actions may be influenced by the perception that COVID-19 is at least partially a human-caused illness. If so, the significance and relevance of our findings may go beyond hypothetical human-caused car collision case scenarios.

\section{Conclusion}

This study addressed the highly important and timely issue of medical triage from a neglected perspective: health-care providers' decision-making processes. The results of our study suggest that caregivers are aware of the conventional rules of medical triage, such as the "worst-first" principle, but when presented with specific concrete challenging dilemmas their choices may be guided by personal intuitions and viewpoints. Thus, in "real life" highly emotionally loaded emergency situations, subsequent medical treatment allocation may be influenced by subjective value-oriented considerations. Even if there is a disparity between our findings and caregivers' "real life" behavior, our study should serve as an alerting call to healthcare providers and policymakers. Further research with regard to "real life" dimensions of triage is required. In addition, there is a need to invest resources and effort to ensure that medical treatment is appropriately allocated in an ethical manner. Health care providers should be taught to reflect upon their personal values and moral intuitions. These individual values and moral intuitions should be openly shared, discussed and respected by colleagues and medical educators. Concomitantly, there 
is a need for educational interventions which aim at minimizing the risk of enabling individual values to inappropriately influence medical triage. This educational effort should be initiated during the early stages of health care providers professional development and continue throughout their professional careers.

\section{Compliance with ethical standards}

Conflict of interest Not applicable.

\section{References}

Alexander, Joshua, and Jonathan M. Weinberg. 2014. The 'unreliability' of epistemic intuitions. In Current controversies in experimental philosophy, ed. Edouard Machery and O'Neill. Elizabeth, 128-145. New York, NY: Routledge.

Alicke, Mark D. 2000. Culpable control and the psychology of blame. Psychological Bulletin 126 (4): 556-574. https://doi. org/10.1037/0033-2909.126.4.556.

Allhoff, Fritz. 2008. Physicians at war: The dual-loyalties challenge. In Physicians at war, 3-11. Springer, Dordrecht. https://doi. org/10.1007/978-1-4020-6912-3_1.

American College of Emergency Physicians. 2017. Code of ethics for emergency physicians. https://www.acep.org/globalassets/newpdfs/policy-statements/code-of-ethics-for-emergency-physicians .pdf.

Baker, Robert, and Martin Strosberg. 1992. Triage and equality: An historical reassessment of utilitarian analyses of triage. Kennedy Institute of Ethics Journal 2 (2): 103-123.

Beauchamp, Tom L., and James F. Childress. 2012. Principles of biomedical ethics, 7th ed. New York, Oxford: Oxford University Press.

Bodansky, Daniel M S. 2009. Ethical dilemmas in triage: A perspective from the Jewish philosophical tradition. Ethics \& Medicine 25 (1): 49-56 (https://search.proquest.com/docview/275119849?acco untid=14765. . Accessed 10 May 2020).

Boyd, Kenneth, and Jennifer Nagel. 2014. The reliability of epistemic intuitions. In Current controversies in experimental philosophy, ed. Edouard Machery and O'Neill. Elizabeth, 109-127. New York, NY: Routledge.

Burkle, Frederick M., and Christopher M. Burkle. 2015. Triage management, survival, and the law in the age of Ebola. Disaster Medicine and Public Health Preparedness 9 (1): 38-43. https://doi. org/10.1017/dmp.2014.117.

Carlsmith, Kevin M., John M. Darley, and Paul H. Robinson. 2002. Why do we punish? Deterrence and just deserts as motives for punishment. Journal of Personality and Social Psychology 83 (2): 284-299.

Christian, Michael D., Laura Hawryluck, Randy S. Wax, Tim Cook, Neil M. Lazar, Margaret S. Herridge, Matthew P. Muller, Douglas R. Gowans, Wendy Fortier, and Frederick M. Burkle. 2006. Development of a triage protocol for critical care during an influenza pandemic. Canadian Medical Association Journal 175 (11): 1377-1381. https://doi.org/10.1503/cmaj.060911.

Chung, Josephin Y M. 2005. An exploration of accident and emergency nurse experiences of triage decision making in Hong Kong. Accident and Emergency Nursing 13 (4): 206-213. https://doi. org/10.1016/j.aaen.2005.08.003.
Considine, Julie, Mari Botti, and Shane Thomas. 2007. Do knowledge and experience have specific roles in triage decision-making? Academic Emergency Medicine 14 (8): 722-726. https:// doi.org/10.1197/j.aem.2007.04.015.

Domres, Brend, Michael Koch, Andreas Manger, and Horst D. Becker. 2001. Ethics and triage. Prehospital and Disaster Medicine: The Official Journal of the National Association of EMS Physicians and the World Association for Emergency and Disaster Medicine in association with the Acute Care Foundation 16 (1): 53-58. https://doi.org/10.1017/s1049023x00025590.

Emanuel, Ezekiel J., Govind Persad, Ross Upshur, Beatriz Thome, Michael Parker, Aaron Glickman, Cathy Zhang, Connor Boyle, Maxwell Smith, and James P. Phillips. 2020. Fair allocation of scarce medical resources in the time of covid-19. The New England Journal of Medicine. https://doi.org/10.1056/NEJMs b2005114.

Feinberg, Joel. 1970. Justice and personal desert. In Rights and reason, ed. Marilyn Friedman, Larry May, Kate Parsons, and Stiff Jennifer, 221-250. Dordrecht: Springer.

Garrouste-Orgeas, Maité, Luc Montuclard, Jean-François. Timsit, Benoit Misset, Marie Christias, and Jean Carlet. 2003. Triaging patients to the ICU: A pilot study of factors influencing admission decisions and patient outcomes. Intensive Care Medicine 29 (5): 774-781. https://doi.org/10.1007/s00134-003-1709-z.

Gilligan, Carol. 1982. In a different voice: Psychological theory and women's development. Cambridge, MA: Harvard University Press.

Gold, Azgad. 2011. Criminal culpability and self-control: Back to M'Naughton. Psychiatry, Psychology and Law 18 (4): 525-536. https://doi.org/10.1080/13218719.2010.509039.

Gold, Azgad, and Rael D. Strous. 2017a. Second thoughts about who is first: The medical triage of violent perpetrators and their victims. Journal of Medical Ethics 43 (5): 293-300. https://doi. org/10.1136/medethics-2016-103496.

Gold, Azgad, and Rael D. Strous. 2017b. Second call for second thoughts: A response to Ardagh and Wicclair. Journal of Medical Ethics 43 (5): 305-306. https://doi.org/10.1136/medethics2016-104085.

Goodwin, Geoffrey P., and Justin F. Landy. 2014. Valuing different human lives. Journal of Experimental Psychology: General 143 (2): 778-803. https://doi.org/10.1037/a0032796.

Gopalan, Pragasan Dean, and Santosh Pershad. 2019. Decision-making in ICU A systematic review of factors considered important by ICU clinician decision makers with regard to ICU triage decisions. Journal of Critical Care 50: 99-110. https://doi. org/10.1016/j.jcrc.2018.11.027.

Göransson, Katarina E., Margareta Ehnfors, Marsha E. Fonteyn, and Anna Ehrenberg. 2008. Thinking strategies used by Registered Nurses during emergency department triage. Journal of Advanced Nursing 61 (2): 163-172. https://doi.org/10.111 1/j.1365-2648.2007.04473.x.

Greenberg, Neil, Mary Docherty, Sam Gnanapragasam, and Simon Wessely. 2020. Managing mental health challenges faced by healthcare workers during covid-19 pandemic. British Medical Journal (Clinical Research Ed.). https://doi.org/10.1136/ bmj.m1211.

Greene, J.D. 2003. From neural 'is' to moral 'ought': What are the moral implications of neuroscientific moral psychology? Nature reviews. Neuroscience 4 (10): 846-849. https://doi.org/10.1038/ nrn1224.

Greene, Joshua D. 2013. Moral tribes: Emotion, reason, and the gap between us and them. New York: Penguin Press.

Greene, Joshua D. 2017. The rat-a-gorical imperative: Moral intuition and the limits of affective learning. Cognition 167: 66-77. https://doi.org/10.1016/j.cognition.2017.03.004. 
Haidt, Jonathan. 2001. The emotional dog and its rational tail: A social intuitionist approach to moral judgment. Psychological Review 108 (4): 814-834. https://doi.org/10.1037/0033-295X.108.4.814.

Hartman, Rhonda G. 2003. Tripartite triage concerns: Issues for law and ethics. Critical Care Medicine 31 (5): S358-S361. https://doi. org/10.1097/01.CCM.0000065130.18337.05.

Hegazy, Soad Mahmoud, Lamiaa Ahmed Elsayed, Tarek Y. Ahmed, and Mohamed I. Rady. 2012. Avoidingpitfalls in trauma triage: Effect of nursing staff development. Life Science Journal 9 (1): $1006-1014$.

Heider, Fritz. 1958. Ought and value. The psychology of interpersonal relations, 218-243. New York: John Wiley \& Sons.

Held, Virginia. 2005. The ethics of care: Personal, political, and global. New York: Oxford University Press.

Huet, Sylvie, Guillaume Deffuant, Armelle Nugier, Michel Streith, and Serge Guimond. 2019. Resisting hostility generated by terror: An agent-based study. PLoS One 14 (1): e0209907. https:// doi.org/10.1371/journal.pone.0209907.

Iserson, Kenneth V., and John C. Moskop. 2007. Triage in medicine, part I: Concept, history, and types. Annals of Emergency Medicine 49 (3): 275-281. https://doi.org/10.1016/j.annemergme d.2006.05.019.

Kelley, Harold H. 1967. Attribution theory in social psychology. Nebraska Symposium on Motivation 15: 192-238.

Kant, Immanuel. 1952 [1790]. Critique of judgement. Trans. Meredith, James Creed. Clarendon Press.

Kelley, Harold H., and John L. Michela. 1980. Attribution theory and research. Annual Review of Psychology 31: 457-501. https://doi. org/10.1146/annurev.ps.31.020180.002325.

Kipnis, Kenneth. 2003. Overwhelming casualties: Medical ethics in a time of terror. Accountability in Research 10 (1): 57-68. https:// doi.org/10.1080/08989620300504.

Klein, Kelly R., Frederick M. Burkle, Raymond Swienton, Richard V. King, Thomas Lehman, and Carol S. North. 2016. Qualitative analysis of surveyed emergency responders and the identified factors that affect first stage of primary triage decision-making of mass casualty incidents. PLoS Currents. https://doi.org/10.1371/ currents.dis.d69dafcfb3ad8be88b3e655bd38fba84.

Knobe, Joshua, Wesley Buckwalter, Shaun Nichols, Philip Robbins, Hagop Sarkissian, and Tamler Sommers. 2012. Experimental philosophy. Annual Review of Psychology 63: 81-99. https://doi. org/10.1146/annurev-psych-120710-100350.

Knobe, Joshua, and Shaun Nichols. 2014. Experimental philosophy. New York: Oxford University Press.

Lederman, Zohar, and T.C. Voo. 2019. Should we prioritise victims over terrorists in medical triage? Journal of the Royal Army Medical Corps 165 (4): 266-269. https://doi.org/10.1136/jramc-2018001009.

Luetge, Christoph, Hannes Rusch, and Matthias Uhl. 2014. Experimental ethics: Toward an empirical moral philosophy. Basingstoke: Palgrave Macmillan.

Mackway-Jones, Kevin, Janet Marsden, and Jill Windle. 2013. Emergency triage: Manchester triage group. Chichester, UK: Wiley. https://doi.org/10.1002/9781118299029.

McManus, Ryan M., Max Kleiman-Weiner, and Liane Young. 2020. What we owe to family: The impact of special obligations on moral judgment. Psychological Science 31 (3): 227-242.

Moskop, John C., and Kenneth V. Iserson. 2007. Triage in medicine, part II: Underlying values and principles. Annals of Emergency Medicine 49 (3): 282-287. https://doi.org/10.1016/j.annemergme d.2006.07.012.

Nadelhoffer, Thomas. 2006. Bad acts, blameworthy agents, and intentional actions: Some problems for juror impartiality. Philosophical Explorations 9 (2): 203-219. https://doi.org/10.1080/13869 790600641905.
Oh, Younjae, and Chris Gastmans. 2015. Moral distress experienced by nurses: A quantitative literature review. Nursing Ethics 22 (1): 15-31. https://doi.org/10.1177/0969733013502803.

Podsakoff, Philip M., Scott B. MacKenzie, Jeong-Yeon. Lee, and Nathan P. Podsakoff. 2003. Common method biases in behavioral research: A critical review of the literature and recommended remedies. The Journal of Applied Psychology 88 (5): 879-903. https://doi.org/10.1037/0021-9010.88.5.879.

Rawls, John. 1971. A theory of justice. Cambridge, MA: Harvard University Press.

Robertson-Steel, Iain. 2006. Evolution of triage systems. Emergency Medicine Journal 23 (2): 154-155. https://doi.org/10.1136/ emj.2005.030270.

Rosenbaum, Lisa. 2020. Facing covid-19 in italy - Ethics, logistics, and therapeutics on the epidemic's front line. The New England Journal of Medicine. https://doi.org/10.1056/NEJMp2005492.

Sapp, Robert F., Jane H. Brice, J. Brent Myers, and Paul R. Hinchey. 2010. Triage performance of first-year medical students using a multiple-casualty scenario, paper exercise. Prehospital and Disaster Medicine 25 (3): 239-245. https://doi.org/10.1017/s1049 $023 \times 00008104$.

Sidel, Victor W., and Barry S. Levy. 2003. Physician-soldier: A moral dillema? Military Medical Ethics 1: 293-312.

Sinnott-Armstrong, Walter, Liane Young, and Fiery Cushman. 2010. Moral intuitions. In Doris, J.M., and Fiery Cushman, ed. The moral psychology handbook, 246-272. Oxford: Oxford University Press. https://doi.org/https://doi.org/10.1093/acprof:oso/97801 99582143.003.0008

Society of Academic Emergency Medicine Ethics Committee. 1995. Ethics of emergency department triage: SAEM position statement. Academic Emergency Medicine 2 (11): 990-995. https:// doi.org/10.1111/j.1553-2712.1995.tb03128.x.

Sperber, Dan, David Premack, and Ann J. Premack. 1996. Causal cognition: A multidisciplinary debate. Oxford: Clarendon Press. https ://doi.org/10.1093/acprof:oso/9780198524021.001.0001.

Stich, Stephen, and Kevin P. Tobia. 2016. Experimental philosophy and the philosophical tradition. A companion to experimental philosophy 5-1. https://ssrn.com/abstract $=2543532$.

Swan, Kenneth G., and K.G. Swan. 1996. Triage: The past revisited. Military Medicine 161 (8): 448-452. https://doi.org/10.1093/ milmed/161.8.448.

Sztajnkrycer, Matthew D., Bo. E. Madsen, and Amado A. Báez. 2006. Unstable ethical plateaus and disaster triage. Emergency Medicine Clinics of North America 24 (3): 749-768. https://doi. org/10.1016/j.emc.2006.05.016.

Task Force on Quality Control of Disaster Management, World Association for Disaster and Emergency Medicine, and Nordic Society for Disaster Medicine. 2003. Health disaster management: guidelines for evaluation and research in the Utstein Style. Volume I. Conceptual framework of disasters. Prehospital and Disaster Medicine: The Official Journal of the National Association of EMS Physicians and the World Association for Emergency and Disaster Medicine in association with the Acute Care Foundation 17 (3): 1-177.

Truog, Robert D., Christine Mitchell, and George Q. Daley. 2020. The toughest triage - Allocating ventilators in a pandemic. The New England Journal of Medicine. https://doi.org/10.1056/NEJMp 2005689.

Vergano, Marco, Guido Bertolini, Alberto Giannini, et al. 2020. Clinical ethics recommendations for the allocation of intensive care treatments in exceptional, resource-limited circumstances: The Italian perspective during the COVID-19 epidemic. Critical Care 24: 165 .

Vincent, Jean-Louis. 1990. European attitudes towards ethical problems in intensive care medicine: Results of an ethical questionnaire. 
Intensive Care Medicine 16 (4): 256-264. https://doi.org/10.1007/ bf01705162.

Vincent, Jean-Louis. 1999. Forgoing life support in Western European intensive care units. Critical Care Medicine 27 (8): 1626-1633. https://doi.org/10.1097/00003246-199908000-00042.

Wagner, Jacqueline M., and Michael D. Dahnke. 2015. Nursing ethics and disaster triage: Applying utilitarian ethical theory. Journal of Emergency Nursing 41 (4): 300-306.

Williamson, Timothy. 2016. Philosophical criticisms of experimental philosophy. In J. Sytsma and W. Buckwalter, eds. A companion to experimental philosophy, 22-36. https://doi.org/10.1002/97811 18661666.ch2
Wirth, Mathias, LaurèlHurwitz. RauschenbachBrian, Heinz-Peter. Schmiedebach, and Jenifer A. Herdt. 2020. The meaning of care and ethics to mitigate the harshness of triage in second-wave scenario planning during the covid-19 pandemic. American Journal of Bioethics 20 (7): W17-W19.

Publisher's Note Springer Nature remains neutral with regard to jurisdictional claims in published maps and institutional affiliations. 